\title{
Augusto y el sistema viario hispano: obras de fábrica
}

\author{
José María Álvarez MarTíneZ \\ Museo de Mérida \\ josemaria.alvarez@mcu.es
}

\begin{abstract}
RESUMEN
La acción en materia de calzadas llevada a cabo en el periodo republicano cristalizó con la emprendida por Augusto y continuada por los Julio-Claudios. Numerosos caminos se convirtieron en firmes calzadas, al tiempo que se ejecutaron diversas obras de fábrica para salvar los imponderables topográficos.
\end{abstract}

Palabras clave: Calzadas. Puentes. Legiones. Vía Augusta. Vía de la Plata.

\section{Augustus and the Hispanic Road System}

\begin{abstract}
The action in matters of roads carried out in the Republican period crystallized with the action taken by Augustus and continued by the Julio-Claudian. Many paths became strong roads, at the same time that several building works were executed to save the topographical difficulties.
\end{abstract}

Key Words: Roads. Bridges. Legions. Via Augusta. Via de la Plata. 
La Península Ibérica fue transitada de antiguo por numerosas civilizaciones que dejaron bien marcada la impronta de su paso. ${ }^{1}$ Viejos caminos, que respondían a las vías naturales de comunicación, fueron utilizados para el acceso al interior desde los puntos más favorables, singularmente costeros. Esas rutas fueron poco a poco consolidándose hasta el punto de que puede decirse que las líneas maestras de lo que va a ser el sistema viario romano en Hispania ya estaban esbozadas en este período.

Lógicamente, las acciones bélicas que los itálicos tuvieron que librar en la Península determinaron la atención a las vías de comunicación necesarias para alcanzar los objetivos, como las que transitaron por el valle del Ebro. Conocemos perfectamente los pormenores de estas viae militares republicanas gracias a diversos estudios. ${ }^{2} \mathrm{Al}$ significativo caso del valle del Ebro podrían añadirse otros varios como reflejo de la acción de Roma en la primera fase de la sistematización del territorio peninsular. Sin duda el más significativo fue el de la vía más singular de Hispania, la futura Vía Augusta, cuyo trazado facilitó el avance hacia Carthago Nova y la zona de Castulo, puerta del Sur, de las armas romanas. Luego, más tarde, con motivo de las guerras civiles sertorianas y como demuestran numerosos hallazgos que jalonan el camino alcanzó protagonismo, la calzada que unía Corduba con Castra Caecilia, una vía de comunicación que ya había jugado un papel considerable en el período Orientalizante.

Una serie de fundaciones atestiguan el valor estratégico de esa ruta, que permitía, por un lado, ganar la Meseta desde Córdoba, y, por otro, propiciaba el acercamiento a regiones ricas en metales, como lo son las del Norte y Oeste de la provincia de Cáceres, Alcántara y la Beira portuguesa, que no escaparon al "ojo romano". Esas nuevas colonias y ciudades se establecieron en lugares estratégicos bien determinados como en el caso de Metellinum, obra del opositor al carismático general romano, Quintus Caecilius Metellus, tanto por un cerro, donde se asentó, como por la presencia de los ríos Guadiana ( $A n a$ ), vadeable en este punto, lo que condicionó el paso de la referida vía, y Ortiga que allí desemboca en el primero. ${ }^{3}$ Ese vado dio origen a un puente sobre el que se han expresado ciertas dudas a propósito de su cronología, aunque para nosotros su origen romano parece claro. ${ }^{4}$

Todos los que se han ocupado de la red viaria de la zona ${ }^{5}$ coinciden en valorar este camino como el más importante del área meridional lusitana hasta la reorganización del territorio con Augusto, en la que se prestó mayor interés a otra ruta que comunicaba el Norte con el Sur como fue el iter ab Emerita Asturicam. El interés que las armas romanas prestaron a la zona de La Serena viene avalado por la presencia de diversos castella, fortificaciones y torres que de manera efectiva desde este período y hasta el siglo I d.C. flanquean los principales caminos, sobre todo la vía de comunicación con Corduba.

1 Almagro 2005, 29-43.

2 Herzig 1974, 593-602 (sobre construcción de calzadas y su financiación durante la República).

3 Sobre la colonia metellinensis: HABA Quirós 1998.

4 Sobre el Puente de Medellín, cuyas ruinas se conservan junto al que le sustituyó en tiempos de Felipe III tras la formidable avenida de 20 de diciembre de 1603 que dio al traste con la fábrica romana: GARCíA Y BELLIDO 1953, 407-418, HABA Quirós 1998, 382-397.

5 Gil Montes - Álvarez Rojas 1988, 315, fig. 5. 
Tras los estudios de los últimos años puede decirse que fueron estas razones, motivadas por la existencia en la zona y en la próxima del territorium arsense de numerosos yacimientos mineros, principalmente los de naturaleza plúmbica, las que explican la presencia de estas líneas de carácter defensivo y de control. Estos recintos, probablemente levantados en tiempos de crisis para proteger intereses determinados de claro carácter militar, tuvieron un gran auge en la mitad del siglo I a.C y desaparecen, cuando las circunstancias cambian, a lo largo de las primeras décadas del siglo I d.C. ${ }^{6}$ Es, por tanto, la acción de la Roma republicana en materia de calzadas una empresa ligada indefectiblemente a los intereses militares relacionados con la conquista. Estas realizaciones fueron efectuadas por el estamento militar en muchos casos, aunque los testimonios no son precisamente abundantes. ${ }^{7}$

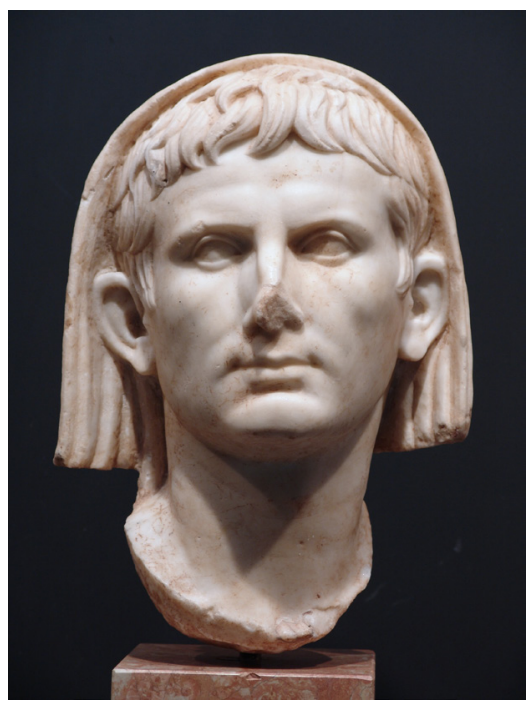

Fig. 1. Efígie de Augusto. Museo Nacional de Arte Romano.

Una vez pacificada la Península Ibérica, hecho que ocurrió definitivamente el año 19 a.C., se pasó por parte de Augusto (Fig. 1) a la puesta en hora romana del territorio, de acuerdo con claros intereses estratégicos, de naturaleza política, ideológica y económica. La experiencia en materia de caminos y soluciones a los imponderables que presentaba la topografía por donde iba a discurrir el trazado de una vía era bien notable. No se resistían a los propósitos de los planificadores las zonas difíciles, escarpadas $^{8} \mathrm{o}$ los obstáculos de las zonas montañosas que no permitían un paso franco y rápido de un lugar a otro a pesar de su cercanía, que fueron solventados con la construcción de criptas. Las corrientes de ríos y arroyos se salvaban por medio de vados, identificados un buen número de ellos en los últimos años. Si no era posible

6 Rodríguez DíAz - Ortiz Romero 1988, 25-41; Moret 1990, 5-43.

7 Le Roux 1982, passim; Le Roux 2002, 261-278.

8 Quilici 1992. 
franquear la corriente se recurría a la construcción de un badén, obra de menor coste que un puente y de los que en Hispania se han identificado varios.

En materia de puentes, la experiencia y los avances del período republicano en cuanto a su estructura, ubicación más conveniente por trazado y, sobre todo, para propiciar la firmeza de las pilas, la vida de un puente, fueron bien desarrollados en estos momentos del inicio del Principado como puede verse en grandes construcciones como el Puente de Narni, ${ }^{9}$ el modelo original de las grandes obras posteriores como Alcántara o la severidad y elegancia de líneas que presentan los edificios de las vías itálicas, como la Flaminia con el Puente de Rimini, de donde partieron, a buen seguro, los modelos que se plasmaron en las construcciones hispanas.

Resulta verdaderamente impactante, como sucede en otros lugares, como la Galia (Strab., IV 6.11), considerar la gran labor que Augusto, que desde el año 20 a.C. detentaba la cura viarum, realizó en la sistematización del territorio peninsular (Fig. 2), lo que se refleja perfectamente en las Res gestae (28). Con la ayuda más que probable de su ministro universal, Marcus Vipsanius Agrippa, el ideólogo, impulsor del conocido Orbis pictus, sistematizó la estructura viaria peninsular, teniendo en cuenta nuevos intereses como eran, entre otros, la fácil comunicación con la Península Itálica, bien por mar hasta Tarraco o Carthago Nova y desde estos puntos, tomando la tradicional Via Heraklea, luego Via Augusta, continuación de la Via Domitia, hasta el proceloso e ignoto Oceáno o el emplazamiento de diversas ciudades, algunas de nuevo cuño, como Augusta Emerita, Caesaraugusta o Asturica Augusta, que se convirtieron en cruces de caminos de Hispania. Desde estas colonias partían, o a ellas llegaban, las calzadas que las unían con los puntos más estratégicos de la geografía peninsular. De los caminos principales, a su vez, surgían otros de menor rango que llegaban a los respectivos puntos territoriales de esas entidades de población.

Fruto de la nueva situación son las nuevas vías, como la de Laminium, o las que unían la capital del conventus caesaraugustanus con otros puntos vitales de la red viaria peninsular como Augusta Emerita o Asturica y, en menor medida, con Pompaelo y Augustobriga. Fue la Vía Augusta la más relevante de las calzadas hispanas y en ella se reflejó abundantemente la ideología imperial como ponen de manifiesto los miliarios conservados desde su "reinauguración" en el año 2 a.C., al parecer.

Numerosas igualmente fueron las obras de fábrica proyectadas a lo largo del camino para salvar los imponderables topográficos antes aludidos y para mostrar, al mismo tiempo, las bondades de la nueva situación. El Puente de Martorell, en la Vía Augusta, en la mansio ad Fines referida en los Vasos de Vicarello, es un ejemplo bien claro de lo que decimos, ${ }^{10}$ con la presencia de un arco en su cabecera que, además de señalar límites territoriales, en este caso los de Tarraco y Barcino, propiciaba la presencia del nuevo orden, de la nueva ideología propugnada por el Principado (Fig. 3).

Construido de acuerdo con los planteamientos técnicos de la época es una obra de carácter militar, al igual que otras del período, como el Puente sobre el Ana en

\footnotetext{
9 Galliazzo 1994.

10 Sobre el Puente existe una amplia bibliografía: Galliazzo 1994, II, $\mathrm{n}^{\circ} 731,342-345$. Ofrece una buena reconstrucción en p. 343; DuRAN FuENTES 2005, 120-125. Son muy valiosos los datos ofrecidos por Fernández Casado: FernándeZ CASAdo 2008, 319-335.
} 
Mérida, y en su caso esa autoría queda perfectamente manifestada por la presencia de marcas de los cuerpos del ejército encargados de su construcción en diversos sillares de sus tímpanos, las legiones IV Macedonica, VI Victrix y X Gemina ${ }^{11}$ Aunque muy deteriorado por diversas fracturas y reformas no precisamente adecuadas, se aprecian los caracteres de su arquitectura sobre todo en las zonas inferiores con sillería almohadillada y en el arco, hoy descarnado, con unos pormenores en su bóveda, a la que le faltan las boquillas, compuesta por tres anillos independientes de dovelas dispuestas en seco y una estrecha rosca en medio de ellas que lo emparentan con otros congéneres del Occidente y, con diferencias de volumen, con el "Arco de Trajano" de Mérida.

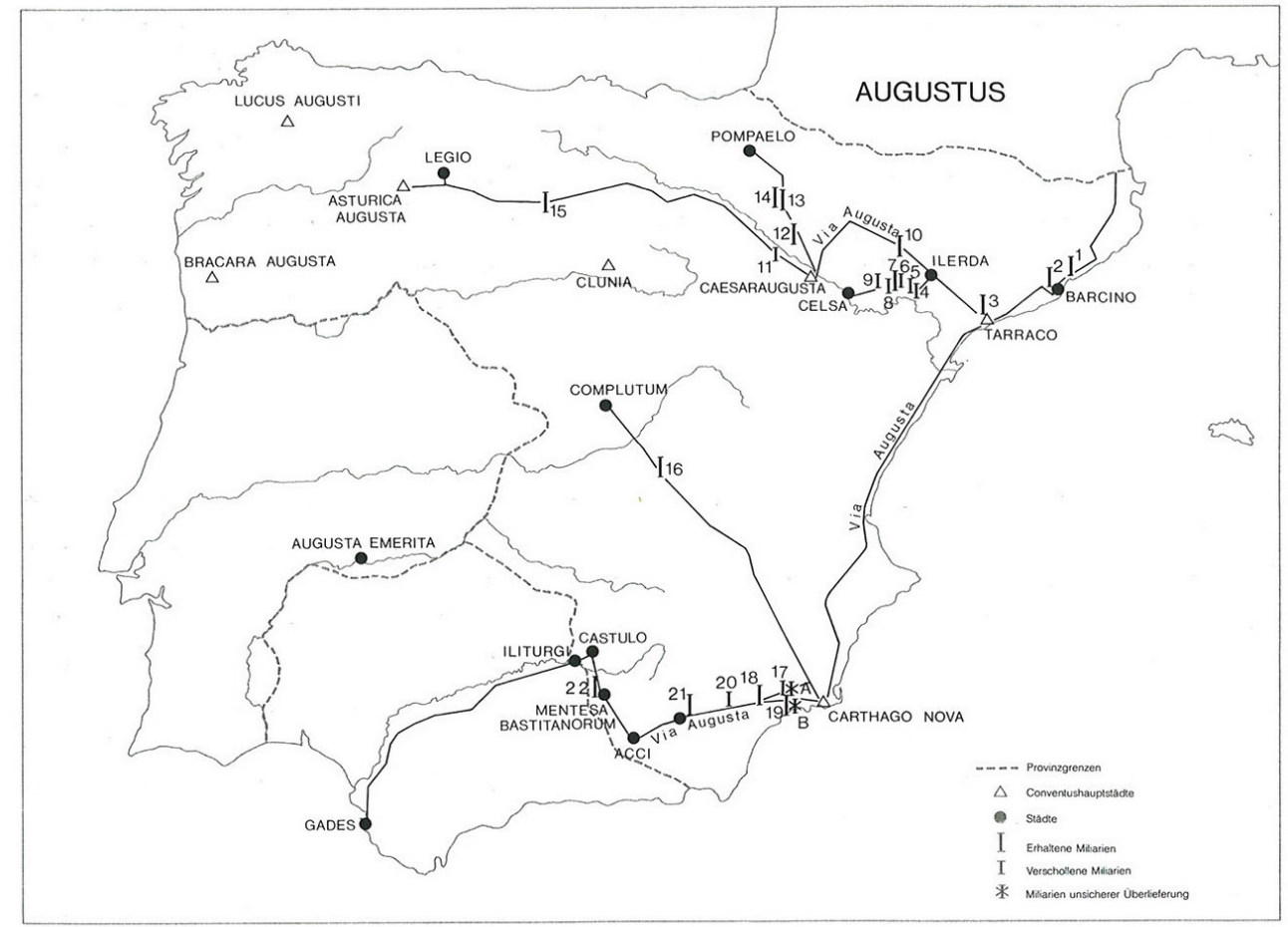

Fig. 2. Mapa de las vías hispanas de época augustea. Hispania Antiqua. Denkmäler der Römerzeit.

La referencia al Arco de Martorell nos lleva a considerar el Ianus Augustus en la misma Vía Augusta, lamentablemente desaparecido y sobre el que se han realizado numerosas observaciones y comentarios. ${ }^{12}$ Son los miliarios los que nos dan cuenta

11 La aparición de marcas de las referidas legiones nos permite, además de proporcionarnos un ejemplo más de la intervención de las unidades militares acantonadas en Hispania, una referencia cronológica centrada entre los años 16-13, tercer viaje de Augusto a la Península y el año 8 a.C. para la construcción del Puente. Sobre estas cuestiones y el carácter del Puente como definidor de los límites territoriales: FABRE ET ALII 1984a, nº1, Lám. I, 3; FABRE ET ALII 1984b, 282-288; GURT - RODÁ 2005, 147-165.

12 SilliÉRES 1990, 795-798; 2005, 305-311. 
de su existencia desde, al menos, el año 2 a.C. Estaba situado junto al Baetis y marcaba el comienzo de la demarcación de la Provincia Ulterior Baetica (Fig. 4). Su ubicación, precisada aun más por otro miliario del tiempo de Domiciano, ${ }^{13}$ al parecer, habría que situarla aguas arriba de Mengíbar (Jaén), cerca de Espelui, donde se produce la confluencia de afluentes del Guadalquivir, el Guadiana Menor, Guadalimar y Gaudalbullón, lo que origina un caudal bien respetable que, para el cruce del río, hubiera precisado de un puente de cierta entidad, quizá de siete arcos sugiere Silliéres, ${ }^{14}$ pero del que nada extrañamente, por lo que conocemos, se ha conservado y del que no hay referencia documental alguna en los períodos posteriores al romano.

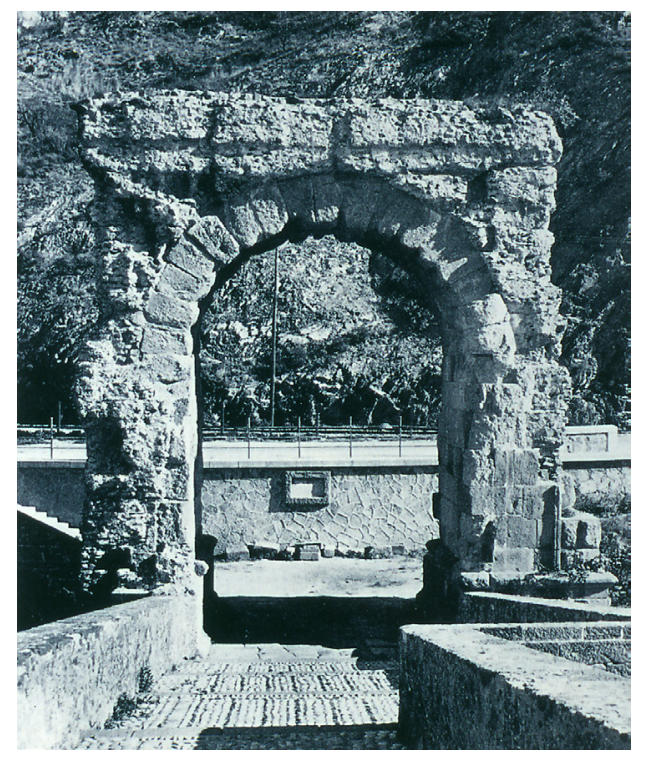

Fig. 3. El arco del Puente de Martorell. Hispania Antiqua. Denkmäler der Römerzeit.

Su papel de limitador entre dos entidades provinciales por donde discurría la Vía es claro, como lo es también su carácter propagandístico y de referencia al Princeps, el pacificador de Occidente, el que llegó en sus conquistas al límite del mundo entonces conocido, ad Oceanum, en su denominación de Ianus Augustus. Es un caso, en este sentido, similar a otros ejemplos bien conocidos como los referidos por las fuentes clásicas o los que han llegado hasta nosotros como el propio Arco de Martorell y otros ejemplos: Cabanes, ${ }^{15}$ Bará. ${ }^{16}$ Los nombres asociados de Ianus et Augustus nos acercaría a una acepción del culto imperial.

13 Imperator Caesar, divi Vespasiano f(ilius), Domitianus Aug (ustus), Germanicus, pontifex maxsumus, tribuniciae potestatis viiii, imp(erator) xxi, co (n) $s$ (ul XV, censor perpetuus, $p$ (ater) p(atriae), ab arcu unde incipit Baetica, viam Augustam militarem vetus(t)ate corruptam restituit.

14 Sillières 1990, 687.

15 Arasa Gil - Abad Casal 1989.

16 Dupré i RaVentós 1994. 


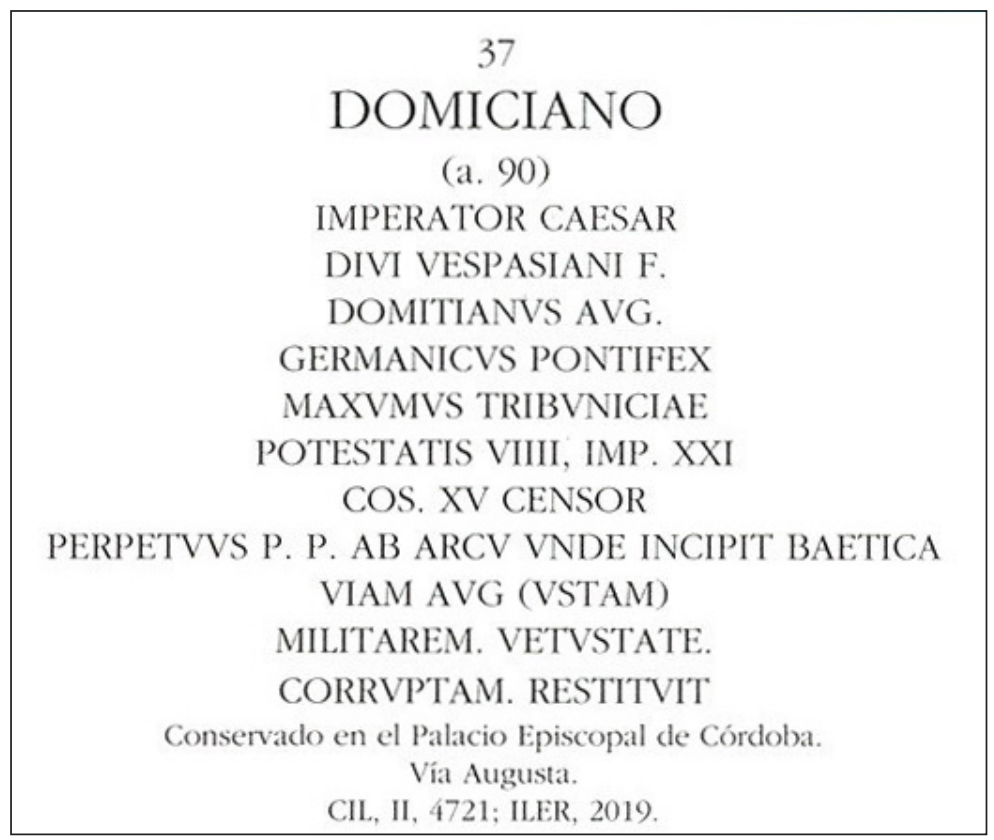

Fig. 4. Texto de un miliario de la Vía Augusta con referencia al Ianus Augustus. Conservado en el Palacio Episcopal de Córdoba. CIL II, 4701.

Debió ser un edificio bien notable y se constituyó, como adelantábamos, en referencia a la nueva situación política, al igual que sucedió con otros arcos similares, ${ }^{17}$ como el de la extremidad de la Vía Flaminia en honor de Augusto, en el año 27 a.C., otro sobre el Puente Milvio, que marcaba el comienzo de la ruta a la salida de Roma, Rimini, Benevento, en el punto de partida de la Vía Appia Traiana. Otros arcos, en fin, se ubicaron en los puentes, bien a la salida o la entrada de los mismos.

Y aquí, al menos a nosotros, nos surge una duda más o menos razonable: ¿estuvo el Arco en el supuesto, y probablemente existente, puente? ¿Su ubicación fue, aunque cercana, fuera de la fábrica? Casi todos los que se han referido a este punto se decantan por la primera solución, dentro de la incertidumbre en la que nos movemos. Incluso, Silliéres, tomando como referencia una conocida moneda del 17/16 a.C. que reproduce en su anverso un puente con un arco coronado por una cuadriga conducida por Augusto en el momento de ser coronado por la Victoria, aventura que pudo tener un carácter similar el Arco de la Bética, que en su coronación pudieron haberse establecido estatuas y se decanta por considerarlo un edificio de culto a la divinidad augusta, Ianus Augustus, acaso con un altar en el interior. ${ }^{18}$ Podría haber contado, igualmente, con una decoración relivaria con referencia al Princeps y sus hechos más notables.

17 SilliÉRES 2003, 275.

18 SilliÉRES 1990, 278. 
En su carácter de culto u homenaje a Augusto inciden igualmente Ramón Corzo y Margarita Toscano, ${ }^{19}$ al analizar la Puerta de Córdoba en Carmona, quienes sospechan que el Ianus Augustus pudo haber contemplado un tratamiento similar, en tanto que la vecina Puerta de Sevilla contó con un templo en su interior. Con relación a lo que antecede, en referencia concreta al carácter que pudieron tener tanto el Arco del Puente de Martorell como el Ianus Augustus, además de constituirse en los definidores de límites entre territorios, es el propagandístico y de exaltación del Princeps, cuyos homenajes se suceden tras Actium. Y a esos arcos levantados en lugares significativos de las calzadas habría que añadir otros muchos que se erigieron para reconocer su aura divina en otros lugares como las vías urbanas de la época.

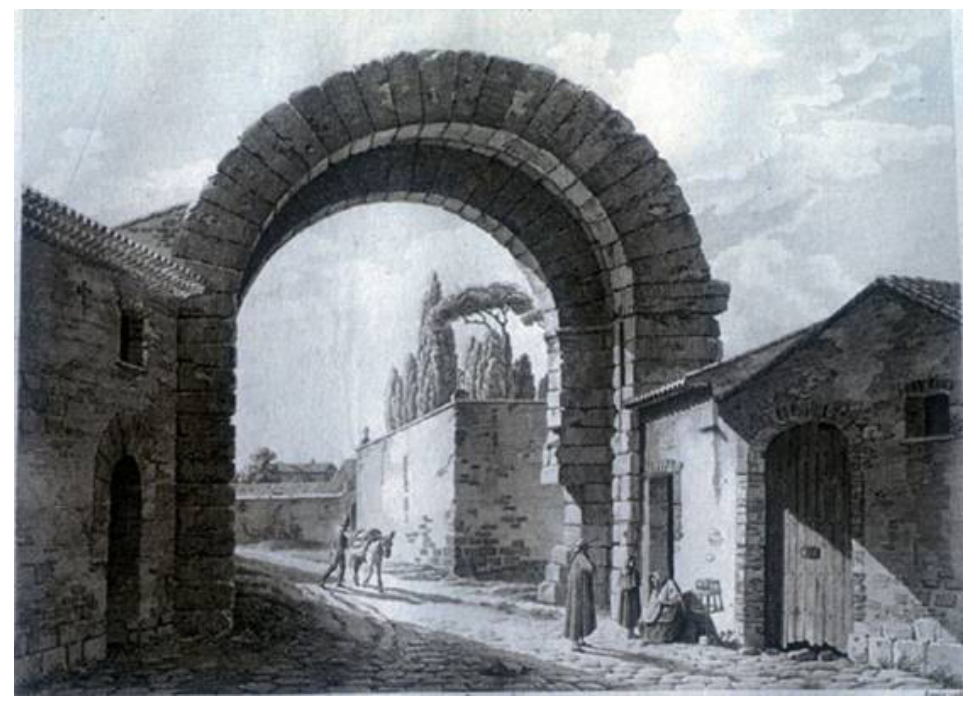

Fig. 5. El “Arco de Trajano” en Mérida. Según De Laborde.

Uno de los posibles ejemplos, al que hemos prestado atención últimamente, ${ }^{20} \mathrm{es}$ el del llamado "Arco de Trajano" en Mérida, dispuesto sobre la vía principal de la Colonia, el kardo maximus como parecen explicar tanto el ninfeo monumental ubicado en su extremo septentrional como su trazado por el Foro colonial bien señalado por monumentales fuentes y su apreciable longitud (Fig. 5). En su día nos fijamos en el sentido que pudo tener el referido arco y nos decantamos por considerarlo, entre otras posibilidades, como la entrada a un recinto sacro o a un foro, sin desechar la idea de que pudo ser un arco urbano que marcaba límites. ${ }^{21}$ Con posterioridad, Antonio Pizzo, en un estudio sobre la fábrica, ${ }^{22}$ abundaba en esas ideas y lo relacionaba claramente, como nosotros lo hicimos en su día, con la entrada a ese recinto sacro,

19 Corzo Sánchez - Toscano San Gil 1992, 103.

20 Álvarez Martínez - Nogales Basarrate 2011, 203-229.

21 Álvarez Martínez 1982, 64-66.

22 Pizzo 2008. 
a un templo dedicado al divus Augustus, a lo que parece, cuya existencia no se conocía cuando expresamos nuestra idea, pero que descubrimos más tarde. Para Pizzo ese arco formó parte del proyecto de remodelación de la zona, que fue amortizada para levantar el referido templo y fue construido en época tiberiana, período en el que hay que situar la construcción del templo.

Por los resultados de las excavaciones dirigidas por el Dr. Mateo ${ }^{23}$ hemos podido conocer cómo el lugar estuvo ocupado por unas viviendas que serían adquiridas para constituir el aludido recinto, el templo y su temenos. También, aunque estos datos ya pudieron ser conocidos por el Dr. De la Barrera, ${ }^{24}$ que el kardo maximus fue amortizado en esa zona, ${ }^{25}$ a partir del Arco, para establecer una escalinata que llegaba al pronaos del templo de culto imperial. En esos trabajos se pudo determinar la anchura del kardo maximus, nunca eliminado, que correspondía exactamente a la que ofrecía el vano central del arco, por lo que no es difícil aceptar la correspondencia de uno y otro.

La fisonomía arquitectónica del Arco nos conducía a un período inicial de la colonia, no necesariamente posterior, aunque las diferencias puedan ser escasas. Igualmente nos fijamos, como otros así lo hicieron, en que los paramentos de sillares de granito ofrecían huellas de ciertos rebajes y preparaciones para ajustar en ellos un revestimiento marmóreo, cuyos restos se aprecian perfectamente en la parte inferior del pilón derecho del arco. Esa operación de cambio, de revestimiento marmóreo, aplicada en un momento posterior a la erección del arco no ofrece dudas, al menos a nosotros. Parece claro que cuando se proyectó la construcción del complejo de culto imperial y se amortizó el trazado del kardo maximus por ese espacio, el Arco, antes de ser eliminado, pasó a desempeñar otra función, la de acceso al recinto sacro recientemente constituido.

El hecho de la existencia de un arco sobre una de las vías principales de la colonia Augusta Emerita no es ciertamente inusual, antes al contrario, porque existen numerosos ejemplares que enfatizaron las vías principales de diversas ciudades romanas, varios de ellos levantados en homenaje al fundador del Imperio y a su familia, tras Actium, en la Península Itálica y en otras provincias, práctica que continuó con Tiberio. ${ }^{26}$ Del mismo modo, la presencia de un arco sobre una vía principal, en la primera época augustea, se relacionaba igualmente con su función de indicador de medida de una larga calle, como era el caso del kardo maximus emeritense. ${ }^{27}$ Otro ejemplo cercano fue el de los arcos levantados sobre los puentes del período. ${ }^{28} \mathrm{Y}$ a propósito de la fábrica emeritense y la arquitectura de su tiempo, hemos reparado en la similitud, aunque salvando proporciones y algún detalle de variante, que existe entre la bóveda del Arco de Martorell y la del emeritense que conviene a la misma

23 Mateos Cruz 2006, 146-153. Excavaciones realizadas por Dr. Mateos y sus colaboradores, los Dres. Pizzo y Cordero.

24 De la Barrera 2000, 172-173.

25 Mateos Cruz 2006, 152-154.

26 ROEHMER 1997, 19 ss; CAPRARIIS 1993, 93-114.

27 Sobre la función de estos arcos, entre ellas la de indicadores de vías principales, véase: De MaRía 1988, 81-85; KüPPER.BÖHM 1996, 178.

28 KLEINER 1991, 182-192. Para el caso de los ejemplos hispanos, 188. 
fecha, augustea, que es la que se ha asignado al Arco de ad Fines y la que nosotros consideramos para el emeritense.

A lo largo del trazado de la Vía Augusta numerosas obras de fábrica se levantaron para mejorar el tránsito de la Vía y solucionar los obstáculos que se presentaban, sin olvidar otras con ese carácter ideológico antes enunciado. Pero fueron los puentes los que alcanzaron mayor significado como uno de los símbolos de esta reorganización que vino de la mano de la pax Augusta. ${ }^{29}$ Fueron obras netamente utilitarias y acordes con el obstáculo que debían salvar; de ahí su estructura sencilla o su carácter ciertamente monumental. De este primer período destacamos los más significativos. El puente de la Colonia Patricia, conocido popularmente como el Puente de la Calahorra, ${ }^{30}$ fue un ejemplar bien notable, cuya existencia, aunque desconocemos cómo sería entonces su fisonomía, probablemente lígnea como apunta Ángel Ventura, ${ }^{31}$ parece atestiguada ya en torno al año 46 a.C., al ser citado en el Bellum Hispaniense (Fig. 6).

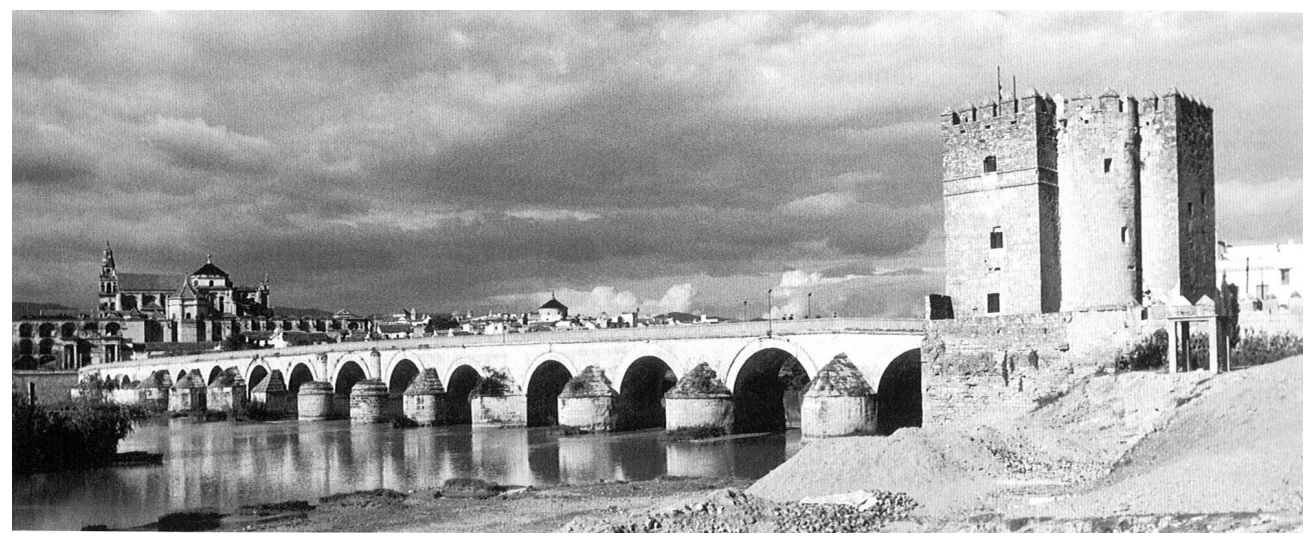

Fig. 6. El Puente romano de Córdoba. Vista aguas abajo. Fernández Casado, Historia del puente en España. Puentes Romanos.

Diversas refacciones obligadas por las avenidas del Guadalquivir y por acontecimientos bélicos llegaron a enmascarar su fisonomía primitiva, hasta el punto que es preciso recurrir a descripciones de cronistas árabes, al-Idrisi entre ellos, para tratar de acercarnos a su realidad, con sus 17 arcos que cubre una longitud cercana a los 300 metros, muchos de los cuales, tras las reformas, adoptaron la forma apuntada. Lo original sólo es perceptible en algunos arcos cercanos a las orillas y en la rosca de las dovelas.

El Puente de Villa del Río, a pesar de no ofrecer la monumentalidad que apreciamos en el de Córdoba, es, quizá, el más interesante del grupo que analizamos por

\footnotetext{
29 NÜNNERICH-ASMUS 1993, 121-143.

30 Sillières 1990, 659-664; Corzo - Toscano 1992, 113; Galliazzo 1994, II, nº 652, p. 326; Fernández CASAdo 2008, 253-274.

31 Ventura 2008, 297.
} 
los caracteres de su construcción. ${ }^{32}$ (Fig. 7) Sus refacciones son apreciables, pero la fisonomía del puente aparece bien clara, con sus cuatro arcos y los dos arquillos de aligeramiento de las aguas, las de un arroyo que en diversos momentos ofrecía un caudal bastante abundante y esta circunstancia hubo de ser muy tenida en cuenta como parecen indicar los sillares engatillados, para enlazar bloques, tan peculiares de la obra y objeto de digresiones acerca de la cronología de esa fábrica. ${ }^{33}$ Lo conservado son los arcos, los arquillos y parte de las pilas, que, a lo que parece, se vieron provistas en su día de tajamares redondeados, apropiados para la naturaleza del cauce que había que salvar.

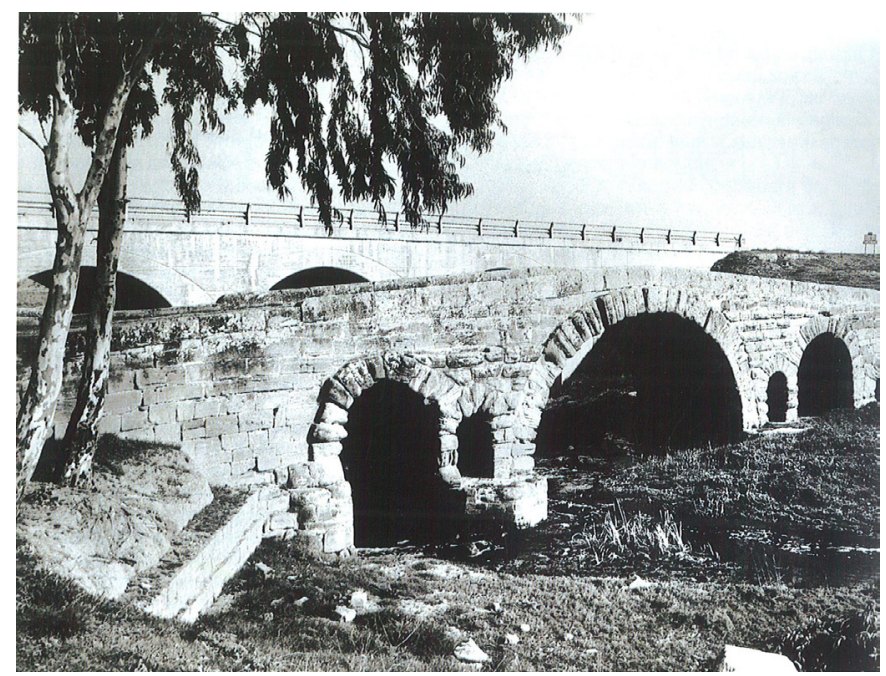

Fig. 7. El Puente de Villa del Río (Córdoba). De J. Latova.

Volviendo al tema de la cronología de la fábrica, la particularidad del engatillado ha hecho pensar a más uno en la posibilidad de que se tratara de una obra tardía, ${ }^{34}$ porque, efectivamente, es un expediente que se puede apreciar en la Antigüedad Tardía $\mathrm{y}$ en el período árabe, pero nos cuesta creer esta posibilidad. El puente ofrece bien a las claras, además, diversos pormenores que determinarían la cronología tardorrepublicana o augustea y que vemos en un ejemplo bien conocido para nosotros como es el Puente de Mérida: el aspecto robusto y macizo de la fábrica, sillares dispuestos en hiladas isodómicas en correspondencia con las dovelas de los arcos, almohadillado de tipo rústico, arquillos de aligeramiento de las aguas como los que apreciamos en la obra emeritense, si bien no se da esa correspondencia que se aprecia en el puente emeritense entre las dovelas de los arquillos y los tímpanos, puesto que en Villa del

32 García y Bellido 1965, 142-149; Sillières 1990, 672-681; FernÁndez CASAdo 2008, 168-173.

33 Silliéres piensa que esta solución, poco utilizada en la antigüedad, no fue otra cosa que una respuesta a la violencia de las aguas: Cfr. 1990, 676-677.

34 DURAN 2005, 126-131 y particularmente 127. 
Río los aliviaderos aparecen fuera de su eje de manera que la rosca es totalmente independiente, mientras que los laterales arrancan de los arquillos de los aliviaderos. ${ }^{35}$

Sillières sugiere una fecha del siglo I a.C., con una posible remodelación que le conferiría su aspecto final realizada entre el 2 a.C. y la época de los Flavios, fundándose en los miliarios de la Vía que señalan los períodos de mayor actividad. ${ }^{36}$ Por su parte, Corzo y Toscano analizan las particularidades de la obra, arcos y pilas con tajamares en ángulo (antes, al parecer, pudieron ser de forma redondeada), su tablero en "lomo de asno" y la disposición de los aliviaderos de las pilas y se decantan por una cronología republicana. ${ }^{37}$ Galliazzo ${ }^{38}$ a su vez, fija la cronología en la primera mitad del siglo I d.C. Para nosotros se trataría de un ejemplar realizado en ese período que antes sugeríamos, tardorrepublicano o augusteo, y su parentesco con el Puente de Mérida, al margen de particularidades de las muescas en sillares y de la disposición de los aliviaderos, nos parece evidente.

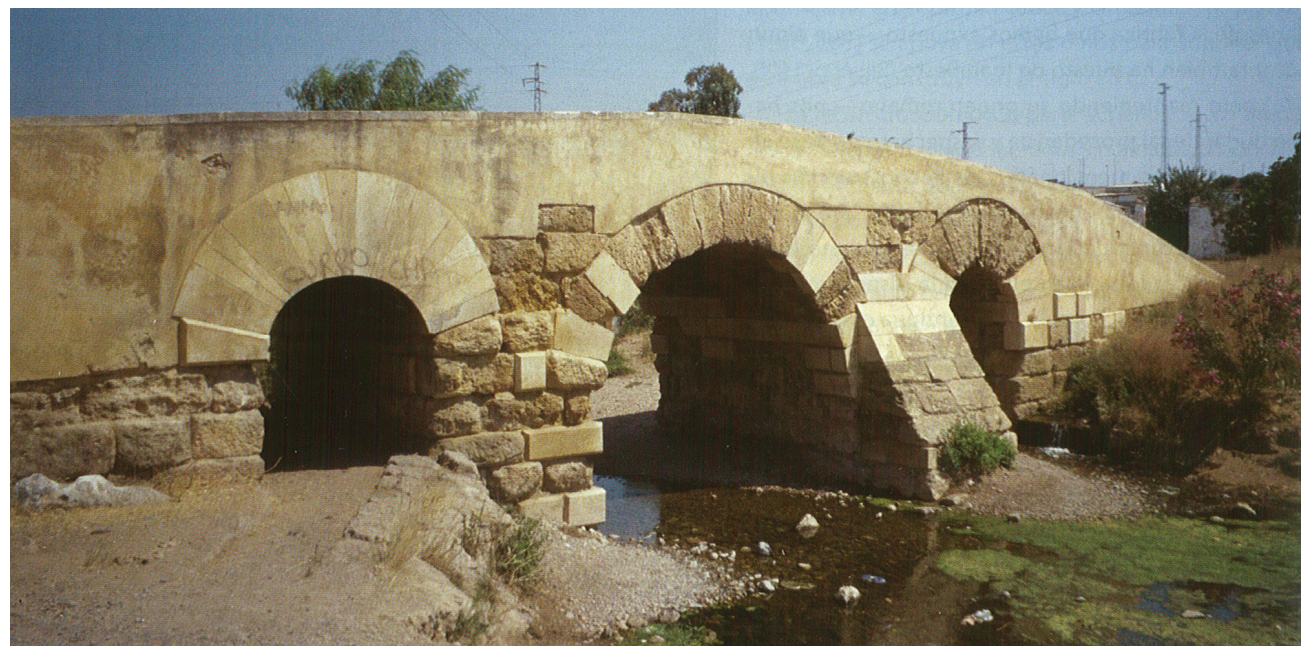

Fig. 8. Puente sobre el arroyo Pedroche. Durán Fuentes, La construcción de puentes romanos en Hispania.

A la salida de la Colonia Patricia el arroyo Pedroche, o Pedroches, obligó a construir un puente que sirviera a la vez a la Vía Augusta y al iter ab Corduba Emeritam, caminos que se separaban exactamente a la salida de la referida fábrica (Fig. 8). ${ }^{39}$ El puente, obra de menor consideración que el de Villa del Río, constaba de tres arcos, de los que se han conservado, con un lamentable deterioro, el central y las partes inferiores de la fábrica. Múltiples reformas, quizá ya desde la Antigüedad, han

35 Corzo - Toscano 1992, 123.

36 Sillières 1990, 678-681.

37 Corzo - Toscano 1992, 123.

38 Galliazzo 1994, II, no 658, 327-329.

39 Fernández Casado 2008, 253; Sillières 1990, 681-687; Melchor Gil 1995, 86-87; Ferrer Albelda 2003, 396-411. 
determinado su actual estado. ${ }^{40}$ Durán alude a lo desacertado de una reconstrucción efectuada hace poco tiempo y se fija en el engatillado de los sillares, aunque en este caso prefiere pensar en una restauración califal ${ }^{41}$ Las características que ofrece la fábrica con su aspecto achaparrado y robusto, la sillería almohadillada muy similar a lo que vimos en el Puente de Villa del Río nos invitan a pensar en una cronología de comienzos del Principado.

Por fin, del elenco de puentes que consideramos que por sus características formales podrían corresponder al tiempo de Augusto, uno, el Alcantarilla, nos ofrece una evidencia epigráfica bien valiosa. El puente ${ }^{42}$ salvaba una corriente fluvial situada entre Orippo (Utrera) y Ugia (Torres Alocaz) a unos 40 kilómetros de Sevilla. Lamentablemente se presenta en mal estado, muy rehecho y cubierto en parte por aluviones, pero su aspecto, macizo y con una arquitectura bien cuidada, revela bien su pertenencia al período que tratamos, avalado además por la referida inscripción: Augustus pontem / dedicavit. ${ }^{43}$

\section{La Vía de la Plata}

En la demarcación de lo que con el tiempo se denominó "Vía de la Plata", el iter ab Emerita Asturicam gozó de especial importancia a raíz de la fundación de la colonia emeritense. Sus vicisitudes son conocidas por los documentos existentes, principalmente sus miliarios, en su día objeto de estudio por parte de Carmen Puertas, y que nos dan cuenta de los trabajos realizados a partir de Tiberio, con Nerón, en el momento en el que ocupó el cargo de legatus pro praetore provinciae Lusitaniae, Marcus Salvius Otho y Trajano, período especialmente fructífero por el buen número de puentes entonces construidos a lo largo de su recorrido, sin olvidar la etapa final de los Flavios.

Fue la fundación de la colonia Augusta Emerita, acaecida en el año 25 a.C., tras la conclusión de una de las fases más importantes de las guerras cántabras (Cas. Dio, 53.25.2; Isid., Etim. 15.1.69), como speculum ac propugnaculum imperii Romani, una consecuencia de la ordenación del territorio en el Noroeste peninsular y fruto de una intención de orden político y económico de especial relevancia.

La idea de glorificar a Augusto, el hacedor de las conquistas hasta el límite de las tierras conocidas, hasta el Océano primó de una manera especial y así en la nueva colonia, todas las acciones emprendidas desde sus inicios, e incluso décadas más tarde, tendrían como denominador común la evocación de la figura del emperador. A todo ello habría que añadir otros motivos no menos importantes como los de carácter económico al constituirse el referido iter y su prolongación al Sur, la Vía que unía la desembocadura del Ana con Emerita en un camino de vital importancia al unir zonas mineras, desde Riotinto a las Médulas, pasando por Alcántara, la Beira y Salamanca.

40 Galliazzo 1994, II, nº 655, 327. Lo sitúa en la mitad del siglo I d.C.

41 DurÁn Fuentes 2005, 132-134.

42 Sobre el Puente: Sillières 1990, 664-672; Corzo - Toscano 1992, 98; Galliazzo 1994, II, nº 667, 330-331; Durán Fuentes 2005, 135-141; Fernández Casado 2008, 274-277.

43 Galliazzo 1994, II, 330. 
Si esto fue así, también lo fue el sumo cuidado que mostraron los planificadores de la nueva urbe en elegir el lugar de su emplazamiento en una zona que de antiguo era ya un cruce de caminos, que el emperador llegaría convertir en firmes calzadas cuando puso en hora el territorio. Ese lugar, además, contaba con una posición estratégica de primer orden como era el vado del Ana, sobre el que se apearon las pilas de un largo puente, de clara facies tardorrepublicana (Fig. 9), ${ }^{44}$ y que se proyectó en ocasión de la fundación de la colonia, en el momento de la organización del territorio bajo la nueva égida. Este nudo de comunicaciones, este "carrefour" de la antigüedad hispana, contemplaba el paso de hasta nueve calzadas reflejadas en los itinerarios oficiales, a las que habría que sumar otras que unían los diversos puntos del extenso territorium emeritense. De más de 800 metros de longitud, lo que le convierte en uno de los más largos del Imperio, ofrece características formales bien definidas que lo encuadran en los planteamientos de la arquitectura tardorrepublicana y a lo sumo en los de los primeros momentos del Imperio, con paralelos claros en el área itálica, de donde procedían las maestranzas encargadas de su diseño y ejecución (caracteres de la fábrica emeritense).

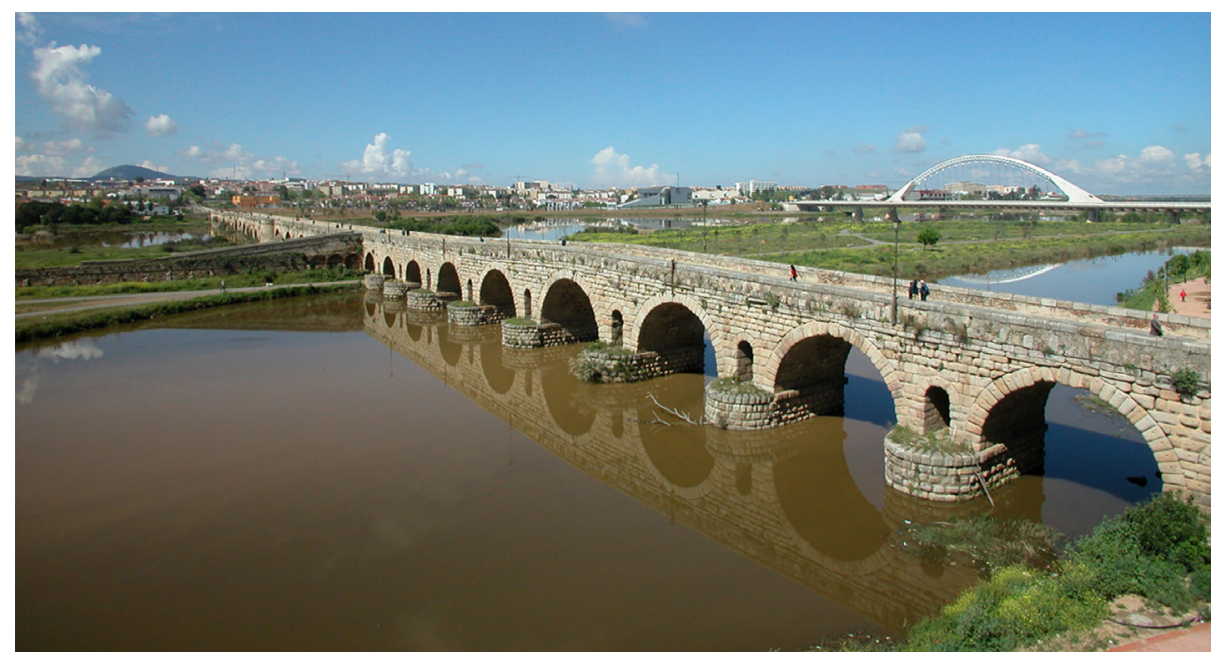

Fig. 9. El Puente sobre el Ana. C. López.

Algo singular en el Puente de Mérida fue la existencia, a partir del décimo arco, de un macizo o malecón que unía los dos tramos de arcuationes en los que se estructuraba la fábrica (Lam. 10). Dicho malecón se protegía por un poderoso tajamar, a manera de "proa de galera", como lo denominara el historiador local Bernabé Moreno de Vargas. La razón de su existencia podría explicarse, por un lado, y de manera principal, por la falta de cimentación en la zona, terreno quebradizo que no propiciaba la firmeza de las pilas, y por la posibilidad de acercar la corriente del agua a las murallas

44 Álvarez Martínez 1983; Feijoo 1997, 321-337. 
de la ciudad, por donde desaguaban las cloacas. En todo caso, la parte ocupada por el tajamar pudo ser aprovechada, por medio de un relleno artificial que situaba el espacio a la altura del tablero de la calzada, para transacciones comerciales, a la manera de un forum boarium, como parece explicar la tradición que se ha mantenido en ese lugar durante siglos y el nombre de nundinae con el que se designó al recinto.

El tajamar, en franco y progresivo deterioro, fue prácticamente destruido en el curso de una gran avenida del río acaecida en el mes de diciembre de 1603. Tras el análisis de los estragos producidos por el río, el ayuntamiento de la ciudad tomó el acuerdo de construir cinco nuevos arcos, por lo que, como referirá el citado cronista emeritense, "las puentes quedaron hechas una". Este puente se constituyó en un símbolo de la bondad de los nuevos tiempos y, en la reorganización augustea del territorio, tuvo el carácter de aglutinador de todas las calzadas de la región entonces determinadas; fue el comunicador entre las zonas del Sur y las del Noroeste, tan vitales para la economía romana, y el vigía constante de la presencia romana en estas tierras. Acaso en un arco, que pudo existir a la entrada por la orilla opuesta a la ciudad, pudo estar ubicada una inscripción relacionada con el emperador.

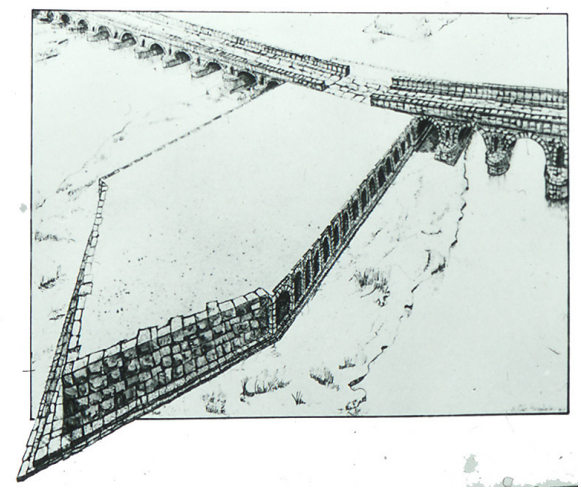

Fig. 10. Reconstrucción del tajamar del Puente. Según Álvarez Martínez, dibujo: Julián Hernández Ramírez.

Los caracteres de su arquitectura primaron grandemente en la construcción de otros puentes del período de tal manera que puede ser considerado como cabeza de serie de otros congéneres, entre los que podríamos citar los puentes emeritenses tendidos sobre el arroyo de Albarregas (Barraeca), ejemplar notable de cuatro arcos, pero desprovisto de tajamares y de arquillos de aligeramiento, cosa explicable por la poca entidad del curso de agua a salvar, y el que se dispone sobre otro arroyo en el camino de Olisippo, conocido tradicionalmente como la "Alcantarilla romana", de un sólo arco. En ambos se aprecian los pormenores de la "manera emeritense", pero su cronología parece posterior a la de su modelo. Son los mismos caracteres que apreciamos en otros puentes como el de Aljucén, en el iter ab Emerita Asturicam, a unos 15 kilómetros de Mérida, lamentablemente destruido, pero, por lo que hemos podido apreciar, muy similar al de Albarregas. 


\section{Bibliografía}

Almagro, M. (2005): "La Vía de la Plata en la Prehistoria”, Anas 18, 29-43.

Álvarez Martínez, J. M.

(1982): "El Foro de la colonia Augusta Emerita". Homenaje a Sáenz de Buruaga, Madrid. (1983): El Puente romano de Mérida, (=Monografías Emeritenses 1), Badajoz.

Álvarez Martínez, J. M. - Nogales Basarrate, T. (2011): “Augusta Emerita en tiempos de Cornelius Bocchus", [en] J. L Cardoso - M. Almagro Gorbea (eds.), M. Lucius Cornelius Bocchus. Escritor lusitano da idade de prata da literatura latina. Coloquio Internacional de Troia. 6-8 Outubre 2010, Lisboa-Madrid.

Arasa Gil, F. - Abad Casal, L. (1989): L'arc romà de Cabanes, Castellón de la Plana.

CAPraris, F. De (1993): "Un monumento dinástico tiberiano nel Campo Marzio settentrionale", Bull. Com. 95, 93-114.

Corzo Sánchez, R. - Toscano San Gil, M. (1992): Las vías romanas de Andalucía, Sevilla.

De la BARrera, J. L. (2000): La decoración arquitectónica de los foros de Augusta Emerita, Bibliotheca Archaeologica 25, Roma.

De Maria, S. (1988): Gli archi onorari di Roma e dell'Italia romana, Roma.

Dupré I RAVEnTós X. (1994): L'arc romà de Berà, (=Biblioteca Itálica 20), Roma.

DurÁn Fuentes, M. (2005): La construcción de puentes romanos en Hispania, Santiago de Compostela.

FABRE, G. ET ALII

(1984a): Inscriptions romaines de Catalogne. I Barcelona (sauf Barcino), Paris.

(1984b): “A propos du Pont de Martorell: la participation de l'armée a l'aménagement du réseau routier de la Tarraconaise Orientale sous Auguste", [en] Epigraphie hispanique Problemes de Mèthode et d'edition (Table ronde internationale. Bordeaux, 1981), Paris, 282-288.

FeIJoo, S. (1997): “Aspectos constructivos del puente romano de Mérida", [en] Mérida. Excavaciones Arqueológicas 1.997, Badajoz, 321-337.

Fernández CASAdo, C. (2008): Historia del puente en España. Puentes romanos.

Ferrer Albelda, E. (2003): "El Puente del arroyo Pedroches (Córdoba). Estudio arqueológico". M.M. 44, 396-411.

Galliazzo, V. (1994): I ponti romani, 2 vols, Treviso.

García y Bellido, A.

(1965): "El puente romano de Medellín (antigua Metellinum)", AEspaA 26, 407-418.

(1965): "El puente romano de Villa del Río”, Oretania 7, 142-149.

Gil Montes, J. - Álvarez Rojas, A. (1988): “Aproximación al estudio de las vías de comunicación en el primer milenio a.C. en Extremadura”, T.P. 45.

GurT, J. M. - RodÁ, I. (2005): “El Pont del Diable. El monumento romano dentro de la política territorial augustea". AEspA 78, 147-165.

HabA Quirós, S. (1998): Medellín Romano. La colonia metellinense y su territorio, Badajoz.

Herzig, H. E. (1974): "Probleme des römischen Strassenwessens: Untersuchungen zur Geschichte und Recht”, A.N.R.W1, Berlín, 593 ss. 
KLeINeR, F. S. (1991): "The Trophy on the Bridge and the Roman Triumph over nature", $L$ ' Antiquité Classique 60, 182-192.

KüPPER.BöHM, A. (1996): Die römischen Bogenmonumente der Gallia Narbonensis in ihrem urbanen Kontext. Kölner Studien zur Archäologie der römischen Provinzen. Band 3, Espelkamp.

LE Roux, P.

(1982): L'armée romaine et l'organisation des provincia ibériques d'Auguste a l'invasion de 409, Paris.

(2002): “Armée et société en Hispanie sous l'Empire", [en] G. Alföldi et alii (eds.), Kaiser, Heer und Gesselschaft in der Rómische Kaiserzeit, Suttgart, 261-278.

Mateos Cruz, P. ET ALII (2006): "Informe sobre las excavaciones arqueológicas desarrolladas en la zona", [en] P. Mateos (ed.), El” Foro Provincial" de Augusta Emerita: un conjunto monumental de culto imperial", (=Anejos de AEspA 42), Madrid, 110-112.

Melchor GiL, E. (1995): Vías romanas de la provincia de Córdoba, Córdoba.

Moret, P. (1990): "Fortins, Tours d'Hannibal et fermes fortifies dans le monde ibérique", $M C V$ 26/1, 5-43.

NÜNNERICH-Asmus, A. (1993): "Strassen, Brücken und Bogen als Zeichen römischen Herrschaftsanspruchs", [en] W. Trillmich et alii (eds.), Hispania Antiqua. Denkmäler der Römerzeit, Mainz am Rhein, 121-157.

Pizzo, A. (2008): El Arco de Trajano de Augusta Emerita, (=Serie Ataecina 4), Badajoz.

Quilici, L. - Quilici Gigli, St. (eds.) (1992): Tecnica stradale romane. Atlante tematico di topografia antica, Roma.

Rodríguez DíAz, A. - OrTiz Romero, P. (1988): “Avance la primera campaña de excavación en el recinto-torre de Hijovejo (Quintana de la Serena, Badajoz). El sondeo n ${ }^{\circ}$ ", Norba 7, 25-41.

RoeHmer, M, (1997): Der Bogen als Staatsmonument: zur politische Bedeutung der römischen Eherenbogen des I Jhs. N. Chr., (=Quellen und Forschungen zur antiken Welt. Bd. 28), München.

SILLIÈRES, P.

(1990): Les voies de communication de l'Hispanie méridionale, Paris.

(2003): "Paysage routier, syncrétisme religieux et culte impérial le long des voies de l'Hispanie méridionale: 1'apport de la toponymie", Gerion 21/1, 265-281.

(2005): “Le Ianus Augustus", [en] Mélanges Chevalier, 2. Histoire et archéologie, vols 1.2, 305-311.

Ventura, A. (2008): “Puentes", [en] P. León (ed.), Arte romano de la Bética. Arquitectura y urbanismo, Sevilla, 297. 